ALTERIDADES, 2019, 29 (58): Págs. 47-58

www.doi.org/ 10.24275 /uam/izt/dcsh/alteridades / 2019v29n58/Hita

\title{
La política de odio en Brasil*
}

\section{The politics of hate in Brazil}

\author{
MARIA GABRIELA HITA** \\ JOHN GLEDHILL***
}

\begin{abstract}
The social impacts of neoliberal capitalism combined with colonial legacies have supported the instrumentalization of a politics of resentment on the part of the far-right in many countries. With an ethnographic perspective, we explore in depth how a politics of hate implanted itself in contemporary Brazilian society. With data from a low-income community in Brazil, we analyse the development of the strong polarization that began in 2016, within and between different social classes, which served as the basis for a notable electoral victory by the far-right.
\end{abstract}

Key words: policy of hate, far-right, social resentment, neoliberal capitalism, ethnographical perspectives from below, Brazil

\begin{abstract}
Resumen
Los impactos sociales del capitalismo neoliberal junto con aquellos legados de la época colonial han apoyado una instrumentalización de políticas del resentimiento por parte de la ultraderecha en muchos países. Con una perspectiva etnográfica desde abajo se indaga a profundidad cómo una política del odio se implantó en la sociedad brasileña actual. Con datos de una comunidad de bajos recursos en Brasil se analiza el desarrollo de la fuerte polarización que se dio a partir de 2016 , dentro y entre distintas clases sociales, lo cual sirvió de base para un notable triunfo electoral de la ultraderecha. Palabras clave: política de odio, ultraderecha, resentimiento social, capitalismo neoliberal, perspectivas etnográficas desde abajo, Brasil
\end{abstract}

$\mathrm{E}^{\mathrm{n}}$ n muchos sentidos, la elección de Jair Bolsonaro como presidente de Brasil parece ser un ejemplo del avance de la ultraderecha provocado por las contradicciones de un sistema capitalista que ha dejado de garantizar tanto la seguridad económica como el acceso a una vida digna para todos los ciudadanos de los antiguos centros imperiales, en cambio, lo que se ofrece a las masas del Sur global es la acumulación por desposesión. El caso brasileño es semejante a lo ocurrido en otras latitudes del mundo, en parte, porque la política del odio se nutre del resentimiento de diversos actores sociales, en particular de aquellos miembros de las clases populares, clasificados como "más blancos", que alimentan un tipo de resentimiento fundamentado en la contradicción, agravada en condiciones de inseguridad económica, entre la internalización de la jerarquía de las

* Artículo recibido el 30/01/19 y aceptado el 22/06/19.

** Profesora Titular del Departamento de Sociologia, Programa de Pós-Graduação em Ciencias Sociales (PPGCs) y Programa de Pós-Graduação em Estudos Interdisciplinares sobre Mulheres, Gênero e Feminismo (pPGNEIM). Investigadora del Conselho Nacional de Desenvolvimento Cientifico e Tecnológico (CNPq) en ECsAs-PPGCS-ufBa y coordinadora del (PPGCS) de la Universidad Federal de Bahia. Av. Adhemar de Barros, s/n - Ondina, Salvador - BA, 40170-110, Brasil <mghita63@ gmail.com>.

*** Profesor emérito de la Universidad de Manchester, miembro de la Academia Británica y de la Academia de Ciencias Sociales del Reino Unido. Oxford Rd, Manchester M13 9PL, Reino Unido <John.gledhill@manchester.ac.uk>. 
razas establecida por el colonialismo europeo y el multiculturalismo liberal. ${ }^{1}$ No obstante, el caso brasileño tiene además raíces históricas específicas, las cuales son bien definidas por Boaventura de Sousa Santos en un artículo publicado en el diario argentino Página 12.

Para Boaventura de Sousa, el vuelco hacia la derecha en Brasil es consecuencia de la explosión de tres tipos de bombas de tiempo. La primera sería el legado de una sociedad colonial fundada en la esclavitud, en la que la desigualdad social extrema "nunca [podría] separarse del prejuicio racial y sexual". Los gobiernos petistas realizaron un esfuerzo sin precedentes para desactivar esta bomba, pero, para tener mayor éxito, hubiera sido necesario mantener sus políticas por varias generaciones. Apostando al boom de commodities para financiar sus políticas sociales, la estrategia del Partido de los Trabajadores (РT) no fue sustentable y, una vez que la crisis económica llegó, una élite dedicada sobre todo a la extracción de rentas, con el apoyo de sectores resentidos de la clase media que no deseaban renunciar a sus privilegios, decidió demonizar al рт para poner fin a la amenaza.

La segunda bomba de tiempo identificada por Boaventura de Sousa es cómo fue negociada la transición de la dictadura militar al nuevo régimen democrático, transición que resultaría fallida no sólo por dejar de castigar a sus torturadores, sino también por haber permitido a los militares ejercer un papel constitucional de guardianes del orden, función que últimamente ha sido defendida como justificación suficiente para que realicen intervenciones públicas en la vida política del país. Por lo anterior, la tendencia a calificar al presidente Bolsonaro como un "Trump tropical" no nos parece muy adecuada, pues el modo en que piensa y la inclusión de figuras militares en su gobierno son consecuencia de la explosión de los efectos y resquicios de esta segunda bomba de tiempo. De hecho, la mezcla de posturas autoritarias y de políticas económicas ultraneoliberales adoptada por Bolsonaro es vista por muchos como un retroceso atávico, quizá con mayor similitud al proyecto del gobierno militar chileno de la época de Pinochet, iniciado en 1973, que al proyecto del Estado desarrollista de la dictadura brasileña de 1964, lo que nos lleva a introducir la tercera bomba de tiempo discutida por Boaventura de Sousa: las tentativas de Estados Unidos de recuperar su hegemonía en América Latina, hoy conectada a organizaciones neoconservadoras en la sociedad civil estadounidense y a diversas agencias y sectores del Estado estadounidense.
El papel de las organizaciones de la sociedad civil estadounidenses y su capacidad de aliarse con empresarios brasileños fue visible desde el surgimiento de lo que Maria da Glória Gohn (2017) llama los novíssimos movimentos sociais de la ultraderecha, que empezaron a expresarse en las concentraciones en las calles que tuvieron lugar en Brasil en 2013 y, de modo más notorio, en las posteriores manifestaciones a favor del golpe constitucional de 2016 contra la expresidenta Dilma Rousseff, y en las mentiras tan notables, masivas y organizadamente difundidas contra el PT por medio de las redes televisivas y de la prensa brasileña, multiplicadas de manera exponencial por la gran cantidad de falsedades y calumnias que se viralizaron en redes sociales como Facebook, WhatsApp, Instagram y Twitter. El fenómeno de las noticias falsas (fake news) tuvo una función relevante durante las elecciones para la presidencia a finales de 2018 .

Boaventura de Sousa apunta asimismo la actuación del Departamento de Justicia estadounidense en el fortalecimiento de datos para la operación Lava Jato (car wash) como una prueba del papel del Estado estadounidense en todo este proceso, observando que "el juez Sérgio Moro se transformó en el agente principal de esta intervención imperial". Entonces, no sorprende que el juez Moro haya sido elegido por Bolsonaro para ocupar su nuevo superministerio de Justicia y Seguridad Pública, e incluso fuera visto como un posible y fuerte candidato para heredar el puesto de jefe del Supremo Tribunal de Justicia. Hay cada vez más evidencias de que la proximidad entre el juez Moro y Bolsonaro fue negociada antes de que el segundo turno de esa campaña electoral hubiese comenzado, así como también del hecho de que, desde su inicio, la operación Lava Jato fue politizada como una operación contra Luiz Inácio Lula da Silva y el Рт. La autenticidad de la información dada a conocer sobre este último asunto por Intercept Brasil fue confirmada por diversas publicaciones que no podrían ser consideradas izquierdistas, desde el periódico Folha de São Paulo hasta la revista semanal conservadora Veja.

Aun cuando en Brasil es notable un fuerte resentimiento de las clases medias y elitizadas contra la modesta ascensión social de familias más pobres promovida por gobiernos petistas, cualquier expresión de rechazo, odio y resentimiento surgida de las condiciones de vida cotidianas de sociedades cada vez más desiguales e incapaces de ofrecer esperanzas a las nuevas generaciones se presta a ser amplificada e instrumentalizada políticamente por los movimientos

1 Para una discusión más amplia sobre las causas de este aumento de posturas de la ultraderecha y las características que ha adoptado en Europa y Estados Unidos, véase Gledhill (2019). 
de ultraderecha emergentes que han aparecido en todo el país. A pesar de ello, es importante ir más allá de ese primer análisis de la política del odio "desde arriba hacia abajo".

Con base en nuestras investigaciones etnográficas en una gran favela, llamada Barrio de la Paz, en Salvador, Bahía (entidad federativa del Brasil que dio $72.69 \%$ de sus votos válidos en el segundo turno de la elección presidencial al candidato del Pт, Fernando Haddad), en el resto del artículo buscamos ofrecer una perspectiva complementaria a aquella que brota sólo desde abajo y que expresa una fuerte polarización social alimentada por las nuevas fuerzas de la derecha que operan en todo el territorio nacional y por las redes norte-sur que pretenden fortalecer la regresión social entre grupos y sectores subalternos de la sociedad.

En otras publicaciones (Gledhill e Hita, en prensa) documentamos con mayor detalle cómo los conflictos que afloraron después del golpe de 2016 resultaron en posturas de rabia y odio entre diferentes actores políticos dentro de esa comunidad, dividiéndolos y radicalizando posiciones más a la derecha contra los defensores de posturas más de izquierda. Del mismo modo, documentamos cómo muchos ciudadanos decidieron votar en blanco, pues algunos estaban decepcionados de todos los partidos políticos y a otros les fue negada la opción de votar por Lula. En este análisis se privilegiaron ante todo los datos que esclarecen los mecanismos de la producción de odio entre amigos. Pero antes de entrar en este tipo de análisis, cabe enmarcarlo en el contexto más amplio que supuso el fuerte impacto que tuvo el asesinato de una concejala del Partido Socialismo y Libertad (PSOL) en Río de Janeiro, Marielle Franco. Su muerte se imprimió en los corazones y mentes de muchos brasileños, y en las discusiones y disputas políticas en el interior del Barrio de la Paz a las cuales nos referiremos.

\section{La violencia del odio: tendencias y contratendencias}

El asesinato de Marielle Franco ocurrió en marzo de 2018. Nacida en la favela de Maré, esta mujer negra consiguió ingresar en la Universidad Católica Pontificia, titularse como socióloga y, más tarde, iniciar sus estudios de maestría en Administración Pública en la Universidad Federal Fluminense. Elegida como vereadora (concejala municipal) del Psol en Río de Janeiro, un agrupamiento izquierdista principalmente integrado por militantes de clases medias "progresistas", Marielle era una figura muy popular, tanto en las favelas como entre los sectores de esta clase media progresista. Se ganó el respeto por sus habilidades políticas, así como por su compromiso con la defensa de los derechos humanos de los residentes de las comunidades más pobres y por su acompañamiento a las familias de víctimas de violencia policial. Apoyada por más de 46500 electores, Marielle estuvo en quinto lugar en las elecciones para concejales en términos del número de votos recibido (entre 1500 candidatos) y fue nombrada por sus colegas para encabezar la comisión parlamentaria creada para monitorear la intervención de tropas federales en el sistema de seguridad pública de Río de Janeiro.

Marielle Franco encarnaba todo lo que la derecha brasileña aborrece: el ascenso social de personas nacidas en favelas a través de la educación superior, una de las políticas más importantes de los gobiernos petistas, y que ha estimulado el resentimiento dentro de los grupos sociales que tradicionalmente han dominado las carreras profesionales. Además, en el caso de Marielle, el hecho de que viviera con una pareja del mismo sexo y defendiera una postura feminista, y otras causas socialmente liberales, la hizo más susceptible a la política de odio de la derecha. Los intentos de desprestigiar a esta luchadora social después de su muerte por medio de una descarada campaña difamatoria de fake news (incluyendo acusaciones falsas sobre narcotráfico) mostraron que la política del odio no tiene límites ni escrúpulos. Sin embargo, su asesinato provocó una reacción de repudio nacional, corroborando que el cambio social también ha producido contramovimientos a favor de la tolerancia en Brasil. Símbolo destacado de una transformación relevante en la posición de personas negras en espacios institucionales antes reservados a la minoría blanca, Marielle Franco quebró un paradigma, en opinión de Eliane Brum (2018), a pesar de ser tachada por una jueza de ser otro "cuerpo común" producido por las guerras del narcotráfico. De hecho, una persona con su perfil dejó de ser vista como alguien que podía ser asesinada con impunidad, tornándose una figura cuya muerte fue lamentada y por la cual, en todas las luchas posteriores en las calles, se exigió su esclarecimiento, algo que no entró en los cálculos de los autores intelectuales del crimen. Aunque los brasileños siguen divididos y polarizados, y en ocasiones son más pasivos u omisos, muchas de estas manifestaciones con banderas preguntando quién mató a Marielle hicieron patente que un gran número de ciudadanos fue capaz de conmoverse y salir a las calles a reclamar justicia para una mujer negra que había logrado conquistar un lugar importante dentro de la vida institucional del país mediante sus propios esfuerzos y talentos. 
Sin embargo, el hecho de que el candidato de la ultraderecha consiguiera una mayoría de los votos válidos en 2018 y que los candidatos de la derecha ganasen mayores espacios en el Congreso puso de manifiesto los límites del apoyo al "campo progresista". Los pasos hacia una sociedad más tolerante de la diversidad y más orientada a la búsqueda de la igualdad siguen provocando reacciones violentas. Un claro ejemplo es el cada vez más preocupante fenómeno de los feminicidios y los ataques en las calles contra homosexuales por parte de pandillas organizadas. Además, la desigualdad social continúa generando odio de diversas maneras y en distintos niveles de la sociedad. En una sociedad como la brasileña, donde la ley y la policía sirven principalmente para mantener a los descendientes de los esclavos en su lugar de marginación social por medio de la represión, y las políticas de encarcelamiento en masa promovidas por una clase política sin escrúpulos sirven sólo para aumentar los niveles de violencia y criminalidad, no es de asombrarse que algunos jóvenes pobres y negros experimenten placer al matar a policías, a pesar de que la mayoría de las protestas contra la violencia policial y la injusticia social sea pacífica. Tampoco sorprende que grandes segmentos de la población brasileña odien a todos los políticos por considerarlos ladrones. Otra vez, a pesar de tener sus dimensiones nacionales específicas, este tipo de fenómenos es de mucho mayor alcance, tanto en el Norte como en el Sur global. ${ }^{2}$

\section{Una mirada desde abajo: las perspectivas políticas de las clases "populares"}

Ya dijimos que cualquier tipo de sentimiento de odio y resentimiento que surja de manera espontánea en las condiciones de vida cotidianas de sociedades cada vez más desiguales e incapaces de ofrecer esperanzas a la población se presta a ser instrumentalizado políticamente por los nuevos movimientos de la ultraderecha, minando la posibilidad de mantener formas de gobierno democráticas. Empero, es importante trascender el análisis de la política del odio "desde arriba hacia abajo", perspectiva que puede reforzar la idea de que las masas siempre son "manipuladas" por los medios (convencionales o sociales), a través del clientelismo, o simplemente engañadas por "discursos populistas" (sean de la derecha o de la izquierda). Por ello, ofre- cemos un enfoque complementario desde abajo sobre los modos en que la derecha política puede echar raíces no sólo en los sectores resentidos de las clases medias sino también en algunos segmentos de las clases populares.

Documentaremos las maneras en que los conflictos suscitados después del golpe de 2016 entre líderes y otros residentes de una comunidad pobre produjeron posturas de rabia y odio de diferentes actores sociales, dividiéndolos y polarizando posiciones políticas. En estas circunstancias es importante señalar que, aunque Bolsonaro ganó la elección con 57.7 millones de votos (contra 47 millones a favor de Haddad), más de 42 millones de brasileños votaron nulo o en blanco o se negaron a ir a las urnas; registrándose la tasa de abstencionismo más alta desde 1989.

Hemos realizado investigaciones etnográficas por más de diez años en Barrio de la Paz, una extensa favela de la ciudad de Salvador. En este apartado buscamos desarrollar el tipo de análisis etnográfico necesario para entender cómo pensaron y actuaron grupos populares en el contexto del golpe (Pinheiro-Machado, 2016). Nos apoyamos en datos construidos a partir del acompañamiento sistemático a lo largo de nuestras investigaciones en esa favela, y de la forma de operar de su Foro Permanente de Entidades del Barrio de la Paz (FPEBP), un colectivo del que somos miembros fundadores, y al cual hemos ofrecido asesoría técnica y logística desde 2007, cuando surgió (Gledhill e Hita, 2014). En este artículo seguiremos las disputas y conflictos de líderes del Foro y de la comunidad de Barrio de la Paz entre sí por medio de un análisis de corte temporal de sus posiciones frente a temas y debates políticos tratados en un grupo de WhatsApp, creado a principios de 2015 para discutir cuestiones de interés para el Foro. ${ }^{3}$ A este grupo se han ido sumando otros actores y personajes externos a la comunidad, pero con un interés directo en sus asuntos.

Las comunicaciones a través de WhatsApp han desempeñado un papel cada vez más trascendente en la movilización de novedosos movimientos populares más espontáneos en el campo político brasileño bajo el régimen golpista, pero también fueron un factor esencial en el triunfo de Bolsonaro, pues fueron una vía muy eficaz para difundir falsedades y fake news contra el PT mediante un aparato propagandístico bien estructurado y financiado por empresarios brasileños y organizaciones civiles estadounidenses que apoyan el giro a la derecha en América Latina. Por lo

\footnotetext{
2 Nos referimos al contraste entre países ricos, desde el ecuador hacia el hemisferio norte, y países pobres o subdesarrollados, desde la línea del ecuador hacia el hemisferio sur, como se entiende en una amplia variedad de literatura que aborda estos temas y debates desde la perspectiva de las teorías poscoloniales.

3 Con la finalidad de proteger la identidad de los entrevistados, usamos seudónimos de ellos y de las organizaciones locales.
} 
anterior, es relevante estudiar lo que está pasando en los nuevos campos políticos creados por medio de WhatsApp. Sin embargo, puesto que nuestro equipo sigue efectuando trabajo de campo en Barrio de la Paz, pudimos complementar el análisis con datos de la observación participante y de entrevistas.

Examinaremos cuatro coyunturas diferentes pero entrelazadas. La primera, de marzo a mayo de 2016 , cuando se empezó a debatir el impeachment de Dilma Rousseff. La segunda, entre agosto y octubre de 2016, cuando el senado confirmó el impeachment de la presidenta y terminó con el rotundo fracaso del PT en las elecciones municipales. Durante la tercera, entre noviembre de 2016 y febrero de 2017, el régimen golpista, dirigido por el expresidente Michel Temer, estaba aparentemente dedicado a lograr sus objetivos de imponer un régimen de austeridad fiscal extremo y una "reforma laboral" que aumentaría la precarización del trabajo, eliminando gran parte de las conquistas sociales del siglo xx, aunque no podía aún avanzar con su pretendida "reforma" de la seguridad social. Por otro lado, el desempleo y la pobreza siguieron en ascenso y el país comenzó a percibir y experimentar una crisis cada vez más profunda, tanto económica como política. La cuarta coyuntura nos llevará hasta enero de 2018, cuando el tribunal de justicia de Porto Alegre confirmó la condena del expresidente Lula por el juez Sérgio Moro, aumentando su sentencia original por corrupción y lavado de dinero a 12 años y un mes, a pesar de la destacada ausencia de pruebas para justificarla. Durante este último periodo, los sondeos empezaron a mostrar que Lula ganaría las elecciones presidenciales sin importar quién fuera su contrincante, mientras que Bolsonaro sólo conseguiría un segundo lugar. No obstante, las fuerzas de este último comenzaron a crecer en los meses siguientes, favorecido por una poderosa campaña de odio contra Lula (y el PT), que resultaría en atentados armados contra militantes petistas.

Entre abril y mayo de 2016, la secretaria del Foro -representante de la organización no gubernamental (ONG) Santa Casa de Misericordia-recordó a los demás en el grupo de WhatsApp cuáles eran los objetivos del FPEBP (en el artículo II de su reglamento), cuando buscaba defender el valor del colectivo contra quienes lo criticaban (en especial el presentador de la Radio Comunitaria, Bocão). Desde su espacio, Bocão siempre cuestionaba lo que hacían los líderes de la comunidad y los miembros del FPEBP, acusando a todos de "seudolíderes", tachando al barrio de ser un lugar donde hay mucho cacique para pocos indios. A su entender, cuando problemas reales que llegaban a su radio eran denunciados en el grupo de WhatsApp por él, muy

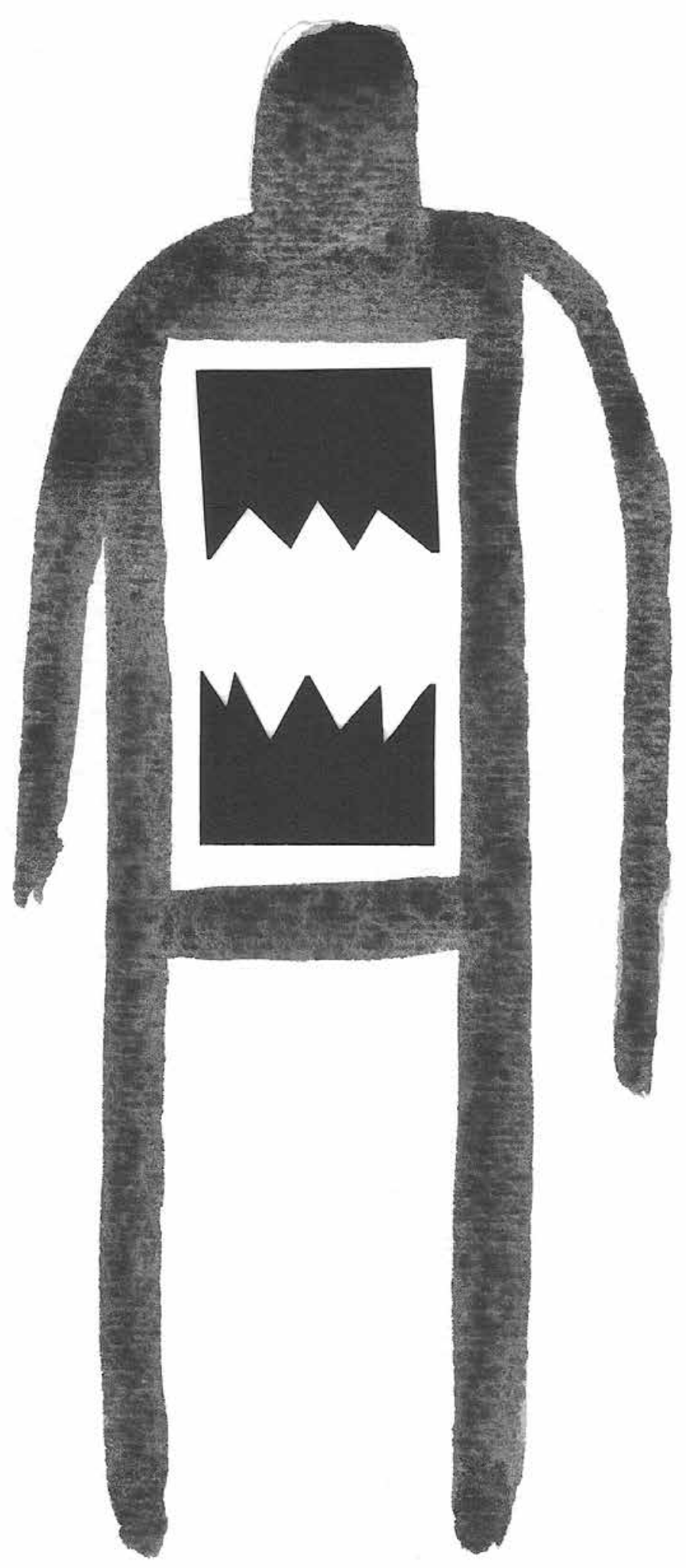


pocos se movilizaban para resolverlos, dedicándose únicamente a participar en reuniones sin pasar a la acción. En el artículo II de su reglamento se define al Foro como un tipo de consejo superior, un espacio de deliberación y debate y busca de consensos sobre los principales problemas del barrio. Cabe entonces a las entidades individuales y su consejo de residentes ejecutar muchas de las resoluciones a estos problemas sin competir entre ellas en la producción de acciones. Mas este punto de apoyar entidades siempre ha sido polémico e interpretado de distintos modos por diferentes participantes, en particular por los recién llegados, que desconocen el reglamento interno y carecen del historial de discusiones anteriores, por consiguiente, se generan frecuentes conflictos y malentendidos.

De manera notable, las posturas de los miembros del grupo de WhatsApp se mantuvieron relativamente firmes durante las dos primeras coyunturas, en acuerdo con sus ideologías y preferencias partidarias. Sin embargo, no fue así durante los sucesos de la tercera coyuntura, en la cual se presentaron grandes derrotas para el PT en las elecciones municipales. Durante marzo y abril de 2016, los debates en el WhatsApp se enfocaron en la validez del impeachment y eran muy acalorados. Por una parte, los que se opusieron al proceso defendieron la democracia y la decisión de las elecciones anteriores, aunque algunos reconocieron errores del gobierno petista, y sobre todo de la presidenta, a veces acusada no sólo de ser menos hábil que Lula políticamente, sino además de haber traicionado su legado. No obstante, este grupo en bloque se contrapuso a varias de las imputaciones, destacando los beneficios que los gobiernos petistas habían traído a los pobres. Por otra parte, quienes defendían que Dilma debía retirarse del gobierno, insistieron en que el impeachment no era un golpe, sino un acto constitucional al que era legítimo recurrir para detener la crisis.

Entre los que criticaron el impeachment se encontraban Mino, de la ong comunitaria socioeducativa Cultura de la Paz; Bocão, de la Radio Comunitaria; Dulce y Mario, influyentes líderes comunitarios ligados a organizaciones católicas laicas; y Lia, candidata del PT a concejala municipal, también vinculada con el catolicismo. Entre quienes defendieron el impeachment, la gran mayoría se mostraba fiel seguidora de la propaganda antipetista transmitida por el noticiero de la Rede Globo, manifestando su rabia contra el PT, como si fuera el único partido involucrado en la corrupción. Este grupo incluía a uno de los comerciantesempresarios más importantes del barrio, Faustão, que había estado muy presente en los debates del Foro en años anteriores, y también a algunas personas que participan en los grupos dedicados a la música y cultura afrobrasileña del barrio, varias de las cuales eran simpatizantes del alcalde Antônio Carlos Magalhães Neto (conocido como Асм Neto).

Elegido en 2012 y reelegido en 2016, АСм Neto pertenece al partido derechista Demócratas (DEM). Es heredero y nieto del ya fallecido Antônio Carlos Mgalhães, el gobernador populista de derecha más notable en la historia de Bahía, quien fuera elegido tres veces como gobernador del estado. ACM Neto es el actual alcalde de Salvador, aunque el gobierno del estado quedó en las manos del PT en 2014, y otra vez en 2018. Siguiendo el ejemplo de su abuelo, ACM Neto ha desarrollado estrategias para construir bases políticas en comunidades pobres, pero de una manera "modernizada", por medio del patronazgo de una cultura negra verdaderamente "popular", incluyendo las actividades que caracterizan a los grupos culturales del Barrio de la Paz. El principal operador político del DEM en la comunidad, y su candidato local a concejal en 2016, Waldemar, originario de São Paulo, llegó al Barrio de la Paz en 2012. Es empleado municipal, encargado de resolver los problemas reportados por los residentes al departamento del ayuntamiento.

Sin embargo, otros líderes de grupos culturales se encontraron entre los críticos del proceso de impeachment, pero con un matiz más suave. Un caso relevante fue el de Caio, coordinador del Foro durante uno de sus periodos de mayor actividad, quien había militado contra las autoridades, cuestionando el papel de la base policial instalada en la comunidad, y opinado sobre cuestiones raciales. Caio está afiliado al Partido Socialista Brasileño (PSB) y fungía como asesor de uno de sus concejales, Silvio Humberto, conocido también por su papel en el movimiento negro militante. Sin apoyar el impeachment, aprovechaba la oportunidad para criticar al PT. Tal vez pensaba en las elecciones futuras, en las cuales el PT podría ser contrincante del PSB, con un discurso semejante al de la líder del PSB bahiano, la senadora Lídice da Mata, quien rechazó la postura de su partido a favor del impeachment en el nivel nacional, y participó muy visiblemente en las marchas en defensa de la democracia y contra el golpe, pero que al mismo tiempo se negó a apoyar de un modo más claro al gobierno petista en aquel primer momento.

En las discusiones de WhatsApp casi no se hacían referencias a las manifestaciones de las calles, salvo por las alocuciones de Bocão, siempre cuestionando datos oficiales y divulgando información que no era difundida por los medios dominantes, buscando especialmente conmover e inquietar a aquellos que creían todo lo que decía la Rede Globo; y las de Renan, ligado 
a proyectos de salud de la familia, quien propagaba noticias del New York Times controvirtiendo la visión y datos acerca de Brasil divulgados por medios nacionales. Los debates giraban sobre todo en torno a si era procedente o no el impeachment, y las posturas resultaban muy polarizadas, de un lado y del otro, como se expresaba en todo el país.

En la segunda coyuntura, los debates sobre el impeachment cesaron, y ya casi nadie hablaba al respecto. La atención estaba centrada en las elecciones. Sólo quienes se habían declarado en contra de la legitimidad del impeachment seguían defendiendo al PT $\mathrm{y}$, de manera indirecta, abogaban a favor del tipo de líderes izquierdistas en los que los residentes podrían confiar como defensores de sus intereses. En la nueva coyuntura, Caio se acercó a este grupo de un modo menos ambiguo. No obstante, hubo contraataques feroces hacia cualquier figura que expresara alguna inclinación por las posiciones de izquierda. Aquellos que tenían fuertes simpatías partidarias intentaban usar el grupo de WhatsApp para hacer propaganda en pro de su partido, provocando a otros a insistir en hacer una regla con la cual prohibir su uso para fines electorales. En ese sentido, la secretaria del FPEBP sostuvo que este espacio y grupo de WhatsApp había sido concebido para compartir y expresar los intereses del colectivo $\mathrm{y}$, por tanto, debía enfocarse únicamente en temas del bien común de la comunidad. Esta postura sólo sirvió para enardecer los ánimos y minar aún más la unidad del colectivo.

Los resultados de las elecciones municipales de 2016 demostraron que la mayoría de los 7720 electores del Barrio de la Paz había retirado el fuerte apoyo que habían dado al Pт en 2012, cuando Асм Neto había sido rotundamente derrotado en ese lugar. En 2016, el alcalde consiguió 63\% de los votos válidos de la comunidad, superando a la candidata del Partido Comunista de Brasil (PCdoB) -nombrada por una coalición de la izquierda que incluyó al PT- por 2000 votos. Sin embargo, casi $29 \%$ de los electores de Barrio de la Paz optó por votos nulos o en blanco. Este resultado, común en todo el país, demostró un aumento significativo de sentimientos "antipolíticos".

Las peleas y vehementes discusiones entre los participantes del grupo de WhatsApp eran por defender a sus candidatos e ideales políticos. Durante este periodo, el PT fue el blanco principal de la rabia y decepción popular. Bocão, de la Radio Comunitaria, quien trabaja como guardia de seguridad en un supermercado en un barrio vecino de clases medias y había sido miembro del PT, seguía respaldando a Lula, no obstante, comenzó a hacer juicios más amargos sobre su partido, criticando todo acto de corrupción política, incluso dentro del PT. Por su parte, Mino continuaba defendiendo a este partido de manera combativa $\mathrm{y}$, por cada cosa que declaraba, provocaba más ira de sus opositores. Fue acusado de estar pagado por el gobierno, motivado por intereses económicos personales, ya que era asesor de Vânia Galvão, del PT, para quien hacía campaña. Como consecuencia, recibió ataques y cuestionamientos a sus proyectos socioeducativos, a pesar de su importancia comprobada en términos de apoyar el acceso de jóvenes de la comunidad a la educación superior. Algunos de sus detractores, que eran miembros de grupos culturales vinculados a $\mathrm{ACM}$ Neto, pretendían humillarlo en lo personal.

No fue por casualidad que en la segunda coyuntura un grupo de "nuevos actores" asociados con grupos culturales ligados a ACM Neto empezara a participar en las discusiones de WhatsApp. Estos jóvenes criticaban fuertemente las propuestas de otros partidos, entre ellas las políticas de cuotas raciales del grupo de Caio, representante en el barrio de Silvio Humberto. Caio, el militante del PSB, se juntó al petista Mino para contestarles, produciendo fuertes y virulentos debates sobre toda clase de asuntos. ${ }^{4}$

La tercera coyuntura estuvo marcada por una postura mucho más crítica del régimen impuesto por el golpe en las discusiones en WhatsApp. De modos diferentes, muchos de los integrantes del grupo, sobre todo los más conservadores, iban disminuyendo su enojo contra el PT y su corrupción, como si fueran dándose cuenta de que habían sido manipulados y engañados. Éste pareció ser el caso de Faustão, el comerciante-empresario, y de algunos de los seguidores de АCм Neto dentro de los grupos culturales, que defendieron cada vez menos al DEM. El haber percibido una profundización de la crisis (ocasionada por las medidas ultraconservadoras del gobierno, junto al incremento de noticias en los periódicos sobre denuncias hechas por testigos que habían negociado un acuerdo de clemencia al declarar en contra de políticos de otros partidos, incluyendo a miembros del mismo gobierno) pareció traer consigo una toma de conciencia. Las posturas durante la tercera fase expresaron una mayor desilusión contra todo político, ya convertido en sinónimo de corrupción,

4 Los temas tratados eran variados: violencia contra la mujer, problemas económicos, asuntos raciales, educativos, narcotráfico, corrupción política y, más adelante, en torno al asesinato de Marielle Franco y la prisión de Lula, entre otros. Los ejes constantes en esta exposición serán la polarización y el conjunto de actores en conflicto, quienes se enfrentaron con diferentes argumentos sobre los temas de interés, y acabarían volviéndose más agresivos con el tiempo, como veremos en un ejemplo con el cual ilustraremos esta dinámica. 


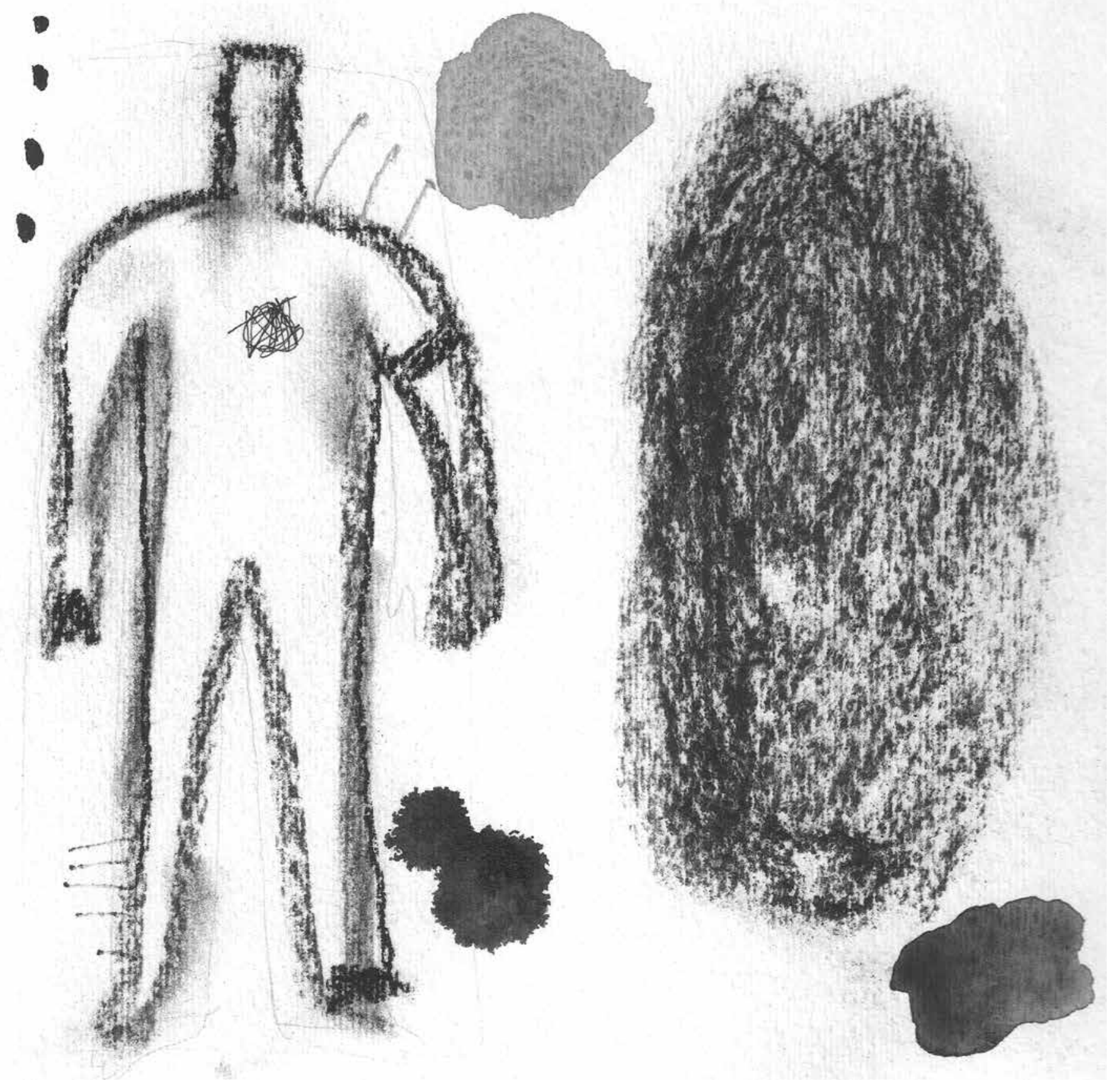

cualquiera que fuera su partido, y ninguno merecía la confianza de la gente. Algunos que no vieron que se trataba de un golpe institucional en la primera fase, optaron por quedarse callados, y otros por disminuir su rabia contra el PT. Finalmente Faustão, enojado, se retiró del grupo, después de una serie de peleas sobre asuntos del Consejo de Moradores, tachando a todos los líderes de falsos, vagos e interesados, por tener puestos pagados.

Llama la atención que este fortalecimiento de posturas antipolíticas no benefició a la izquierda en ge- neral ni al PT en particular, a pesar de que las entrevistas que realizamos durante la cuarta coyuntura exhibieron una gran recuperación de la popularidad personal de Lula dentro del Barrio de la Paz, entre los más pobres y las regiones del noreste de Brasil. Incluso aquellos que sospechaban que los cargos de corrupción en contra de Lula podrían ser legítimos, pese a la debilidad de las pruebas presentadas por el juez Moro y los procuradores en Curitiba, vieron en su regreso a la Presidencia la mejor opción para el país $\mathrm{y}$, sobre todo, para los pobres, ya que el expresidente 
se había comprometido a cancelar las medidas socialmente retrógradas del régimen golpista. Una consecuencia muy significativa fue que aun algunos líderes ligados a ACM Neto declararon que votarían por Lula en elecciones nacionales si ésta llegara a ser una posibilidad. Esto es consistente con la hipótesis de que Lula abrió un nuevo capítulo en la historia del populismo brasileño por ser "del pueblo" y no simplemente una figura, como Getúlio Vargas, quien fuera representante de otra clase social que consiguió ser "popular" por haber convencido a la clase obrera urbana de que tenía interés en gobernar para mejorar sus condiciones de vida. Sin embargo, aunque los sondeos mostraron que Lula disfrutaba de un gran respaldo dentro de distintas clases sociales, hubo una diferencia importante entre el apoyo a Lula y el apoyo al PT y al resto de la izquierda.

Una vez que la candidatura de Lula fue bloqueada judicialmente, la ultraderecha continuó con la tarea de promover el antipetismo en el ámbito nacional, renovando la asociación entre el partido y la corrupción, sacando además provecho de la desilusión con los partidos principales de centroderecha que habían apoyado el golpe, el Movimiento Democrático Brasileño (MDB) y el Partido de la Socialdemocracia Brasileña (PSDB), los cuales perdieron muchos votos. A la vez, la ultraderecha se aprovechó del ya mencionado abstencionismo. En 2018, incluso sin Lula, el PT consiguió un triunfo impresionante en Bahía, confirmando las declaraciones de algunos de nuestros entrevistados de que votarían por el candidato nombrado por el expresidente, en caso de que la justicia impidiera su candidatura. Aunque el noreste mostró la máxima resistencia a la ultraderecha, los resultados nacionales evidenciaron que, en general, los brasileños negros rechazaron a Bolsonaro y su movimiento. Pero esto nos lleva a otra complicación adicional presentada por una mirada desde abajo.

Hemos visto que la política de odio en Brasil se ha nutrido del resentimiento de ciudadanos más privilegiados que vieron en las políticas sociales de los gobiernos petistas una amenaza a dichos privilegios. Por consiguiente, podría pensarse que habría un consenso entre los residentes de una comunidad "pobre y negra”, donde dichas políticas sociales merecerían ser elogiadas y defendidas. En el último apartado de este trabajo usaremos los debates internos de este grupo de WhatsApp en el Barrio de la Paz para mostrar que la realidad fue más compleja. Aunque la mayoría de la población del estado de Bahía podría ser clasificada como "afrodescendiente", este tipo de categorías no nos ayudan a entender cómo se viven las cuestiones de raza, color y fenotipo en la vida cotidiana de una sociedad caracterizada por altos grados de mestizaje, ni tampoco cómo cuestiones raciales se articulan a distintas formas de microdiferenciación social y diversas posturas ideológicas y religiosas. Es a la luz de esta perspectiva que podemos entender por qué ciertas políticas sociales más "progresistas" de los gobiernos petistas fueron capaces de generar conflictos, resentimientos y hasta odio, no sólo en las capas más privilegiadas de la sociedad, sino también entre actores sociales dentro de la misma clase popular.

\section{La producción del odio entre amigos}

Aquí trataremos cómo, en la coyuntura de septiembre de 2016, miembros de dos grupos culturales de hip hop del Barrio de la Paz, que en el pasado fueron uno solo, se identificaron étnico-racialmente y se atacaron de manera feroz por diferencias en sus posturas en temas como las cuotas raciales, las políticas afirmativas y la política nacional en general.

La Tribu Suburbana fue el grupo cultural original de hip hop en esta comunidad, el cual a partir del año 2000 reunía diversos estilos musicales del barrio (en particular hip hop, reggae y música de estilo afro tocada en lugares de culto de candomblé, fiestas y batucadas de playa), distintas performances de danza (sobre todo de tintes folclóricos, grupos de capoeira y baile afro), teatro experimental, poesía, y producción de videos y cortometrajes orientados a temas críticos, en especial raciales. Este grupo tuvo varias escisiones alrededor de 2005, a causa de luchas internas por el restringido acceso a los escasos recursos provenientes de acciones patrocinadas por el Estado y gobiernos del PT, profundizándose cuando aparecieron nuevos grupos culturales con objetivos propios y más demarcados.

Caio continuó siendo el líder y cabeza principal de la Tribu Suburbana, grupo que con el pasar de los años se ha ido dedicando cada vez más a actividades políticas dentro del Movimiento Negro Unificado (MNU) y a la producción de videos y cortometrajes, y cada vez menos a los espectáculos y performances como cantantes de hip hop. Con color de piel muy oscura y autoidentificándose como "negro", Caio fue coordinador del FPEBP en uno de sus momentos más activos y combativos (2010-2012), y trabajó hasta 2018 para el concejal Silvio Humberto, uno de los más destacados militantes del MNU en Salvador, y creador del Instituto Steve Biko, una onG reconocida por haber generado miles de oportunidades para el acceso de afrodescendientes a la universidad en los últimos años.

Mino, otro líder con color de piel morena clara, petista ligado a la concejala Vânia Galvão en aquel 
momento, está asociado con Cultura para la Paz, otro grupo disidente de la Tribu Suburbana y una ONG encargada de acciones educativas y de ofrecer cursos para preparar a jóvenes para el examen de ingreso a la universidad. Con frecuencia, durante la coyuntura de las elecciones de 2016, este grupo se alió al de Caio, para juntos combatir las críticas y acusaciones que recibían de los más recientes y jóvenes integrantes del grupo de WhatsApp, Lelo y Rocco, ambos miembros del grupo cultural Alvéolo, también de hip hop, poesía y teatro experimental, y otra escisión de la Tribu Suburbana, compuesta por tres miembros, todos hombres. Lelo y Rocco, de piel más clara y parda, y los que participan de ese grupo de WhatsApp, se distinguieron de los anteriores por no tener hasta ese entonces ningún cargo político, y por ser fuertes defensores de la línea política del alcalde de Salvador ACM Neto.

Lelo tenía 24 años cuando se unió al grupo de WhatsApp en 2016 (y sólo 13 cuando empezó a cantar en la Tribu Suburbana). Aún era estudiante de escuela pública ( $2^{\circ}$ año de preparatoria) y vivía con su madre. Se mantiene de lo que logra juntar con trabajos informales en el área de la construcción civil. Por ser de los artistas más jóvenes dentro de los grupos culturales del barrio, es conocido por el apodo de Bebé y es muy elogiado, sobre todo por las mujeres, por su talento como escritor de poesía amoroso-erótica y de crítica popular. Él buscaba a toda costa conseguir el apoyo y patrocinio del capitán de la policía de la Base Comunitaria de Seguridad (всS) dentro del barrio (además de los políticos del DEM para los que su grupo hacía campaña) con la finalidad de promover una "batalla de música rap" en la plaza principal de la comunidad, lo cual se conquistó poco después de las elecciones y por medio de otras negociaciones realizadas con el capitán de la всs, luego de una audiencia organizada por el FPEBP y la Asociación de Residentes del Barrio para tratar temas de seguridad en esta misma coyuntura.

Como ya comentamos, una de las discusiones más importantes en el transcurso de las elecciones de 2016 giró en torno de las cuotas raciales y el impacto de las acciones afirmativas, defendidas por los más izquierdistas, que discrepaban de los miembros del grupo Alvéolo, quienes clamaban por acciones más asistencialistas de beneficio inmediato para los residentes más vulnerables del barrio, también saliendo en defensa de prácticas clientelares, por ejemplo, las de pedir asfalto para las calles y servicios de salud gratuitos, como se acostumbra ofrecer en periferias urbanas en época electoral. Fue en el contexto de los debates sobre las acciones afirmativas cuando de modo mucho más explícito Lelo y Rocco se autoidentificaron en términos de color de piel parda y más clara, aun cuando en otros momentos ambos parecían incluirse y reconocerse como pobres de la periferia de Salvador, o, en palabras de Lelo, como "pretos fodidos" (negros jodidos), la forma racializada más genérica en que la sociedad tiende a clasificar a los residentes de las favelas. Para Lelo, todos ellos están excluidos del sistema principalmente por factores socioeconómicos y no por el color de su piel. Al pretender descalificar al MNU por haber promovido la racialización y dividido a la comunidad más que combatir la discriminación, Lelo señaló:

Yo no soy negro, por causa de la melanina. Yo soy pobre jodido, financieramente. Cuotas para negros precisan acabar, tienen que ser sólo para alumnos de escuelas públicas. Luchar por el color de la piel no va a adelantar nada. Blanco jodido en el Barrio de la Paz y en otras comunidades periféricas, queriendo o no, es negro para el IBGE [Instituto Brasileño de Geografía y Estadística], y con todo lo de malo que lo acompaña asociado a ello. Pero a la hora de distribuir becas para cuotistas es tratado como blanco. [Estoy] contra el sistema de cuotas porque nosotros ya sufrimos mucho por ser negros (pretos), pobres y de periferia. ¿Y ahora también tenemos que ser excluidos y sufrir más en los procesos de selección de las cuotas? ¿O pasar a endeudarnos más aún con las becas que nos dan por el sistema del FIEs [Fondo de Financiamiento al Estudiante de Educación Superior] para entrar en universidades privadas? ¡No! Yo lucho para que todo alumno de escuela pública tenga el acceso directo, sin examen, a la universidad. Eso debería ser automático. Además, muchos líderes de movimientos, como el Negro, sobreviven [a partir de] la miseria ajena. El MNU existe hace ya mucho tiempo, pero la mortalidad contra los negros no ha parado. ¿Entonces? ¿Qué han hecho? Y en África también muere mucho albino - que los negros matan, creyendo ser un satanás. El problema no es de color, de melanina, ella es económica. Y las personas ligadas al MNU sólo piensan en su ombligo y sus cargos. Pasadas las elecciones, desaparecen y se olvidan de nosotros.

De modo algo ingenuo y menos informado en alguno de los aspectos que menciona, o incluso hasta mal intencionado -como simplemente aniquilar argumentos de sus contrincantes y opositores políticos a cualquier costo-, en este discurso Lelo reprodujo la clase de argumentos de muchos grupos de la élite blanca contra las acciones afirmativas, y acusó a líderes del MNU involucrados en la implementación de estas políticas afirmativas de apoyarse en premisas que fundamentan un tipo de discriminación de los que más segregan y crean nuevas desigualdades, en lugar de promover un verdadero e importante combate a la 
intolerancia, las discriminaciones raciales y las desigualdades, que, para él-repetía una y otra vez-, eran básicamente económicas. Acusaba a Caio y a Mino de "mamar en las tetas del gobierno". Según Lelo, las políticas afirmativas podrían perjudicar casos como el suyo, hipotéticamente hablando (ya que su contraparte en el debate lo acusaba de no entender cómo funciona la implementación de estos beneficios, donde el color de piel es por autodeclaración), al supuestamente disminuir sus posibilidades de ser uno de los beneficiados para entrar en la universidad si tuviera que competir con un vecino de color de piel más oscuro que la suya, lo cual no parece ser tan probable, al menos en Bahía, donde se juzga que $80 \%$ de la población, según criterios oficiales, son afrodescendientes.

Denunciando la postura de Lelo como errónea, invitaban al joven a conversar en público y a que estudiara un poco más, menospreciándolo al llamarlo Bebé, desinformado, loco (por la forma de actuar, argumentar y repetir mensajes), y lo tildaban de apoyar a los golpistas. Caio, refiriéndose a los ataques de Lelo, se dirigió a Mino para buscar su apoyo con el propósito de defenderse juntos de las acusaciones que habían recibido, asimismo, pretendía reafirmar los impactos positivos de las acciones afirmativas. En tanto que Mino colocó en el WhatsApp un mensaje jocoso contra el presidente golpista Michel Temer, tachándolo de racista y de ir "contra los intereses de los pretos (negros) de periferia, que continúan siendo descartados y asesinados”, Caio le respondió lo siguiente en un audio:

Cuidado Mino [ironizando, riendo y aliando-se a él], que vas a provocar a estos tipos aquí a favor de Michelzinho [Temer] y que están contra las cuotas, el FIEs y todos los programas y conquistas sociales que nos benefician, y que son a favor del decreto de ley de la Escuela sin Partidos. Ellos no tienen idea de todo lo que aún están por perder, cuando lleguen a aprobar la reforma del trabajador y la de seguridad social, que están siendo discutidas. Dejo esa pista (advertencia) aquí. Ellos nos atacan y nos llaman a nosotros de oportunistas. ¡Estos tipos van a quedar locos!! [cuando lean el mensaje de Mino]. Oye, les va a dar diarrea mental. Nosotros somos los que defendemos la Comuna [refiriéndose cariñosamente a la comunidad, pero también a la idea del Bien Común], la favela. Esos locos van a tener que tomar remedio para no tener diarrea mental.

Yo no soy ladrón, corrupto o demagogo, como andan diciendo de todos esos políticos que ellos apoyan. Yo no escondo que tengo un cargo público conquistado con mi sudor, trayectoria y militancia coherente y consistente todos estos años en el MNU. Yo siempre fui y continúo firme en mis ideas y acciones. No busco dividir, pero tampoco soy connivente con políticas de seguridad racistas y políticas absurdas del actual gobierno de corruptos en el poder - y es por eso justamente que los criticamos.

\section{Conclusiones}

En el caso de Brasil, puede vincularse el crecimiento de una política de odio y resentimiento con condiciones históricas fuertemente arraigadas en la historia de este país, pero las contradicciones que acabamos de ilustrar también son fruto de circunstancias contemporáneas. Además son, en parte, producto de esfuerzos bien intencionados de reducir algunas de las grandes desigualdades que han resultado de una relación particular entre clase social y discriminación racial, otra vez arraigadas en una historia nacional específica. La desilusión de los brasileños con la democracia representativa tiene asimismo vertientes nacionales concretas. El golpe negó a un segmento importante de la población la posibilidad de votar por el candidato que sería considerado su representante, y las reglas del juego político existente ofrecieron candidatos con los cuales muchos electores no se identificaban, lo cual promovió el abstencionismo. El principal motivo para no sentirse representado es que se juzga como corrupta a toda la clase política contemporánea, cuyos candidatos capaces de ganar elecciones encarnan los intereses del gran capital o del agronegocio y están a favor de entregar los recursos nacionales a extranjeros.

Sin embargo, el crecimiento de una política de odio $\mathrm{y}$ resentimiento en Brasil se inserta y refuerza dentro de un proceso mucho más amplio. La democracia representativa liberal se encuentra en crisis mundialmente. Es importante contextualizar este proceso en un modelo de capitalismo que parece incapaz de mantener el proceso de acumulación sin aumentar la desigualdad social y recurrir a métodos cada vez más autoritarios para defenderse (Streeck, 2016). En este sentido, el golpe brasileño puede entenderse como un ejemplo más de un proceso global, un proyecto para hacer que la sociedad brasileña acepte que la austeridad y la precarización del trabajo son la única opción. En nuestra opinión, se ha llegado a este punto porque los partidos socialdemócratas, tanto en Brasil (con el PT de Lula) como en Europa, aceptaron las reglas del juego del capitalismo neoliberal. Una vez hecho este pacto faustiano, los intentos de los gobiernos socialdemócratas de aliviar sus efectos sociales negativos no fueron suficientes para mantener sus bases sociales establecidas. Abrieron espacios para 
nuevos movimientos populistas de la ultraderecha, pero también provocaron las reacciones antipolíticas que recientemente han generado altas tasas de abstencionismo en países tan distintos como Francia o Brasil. Los brasileños están hartos de la corrupción, y muchos han perdido la fe en las instituciones y en la posibilidad de mejorar sus condiciones por la vía política electoral.

En general, ni las izquierdas latinoamericanas ni las europeas han podido lidiar con esta situación, a pesar de algunos éxitos locales y del activismo de movimientos sociales que son cada vez más espontáneos y horizontales (y, por lo tanto, difíciles de coordinar e integrar dentro de un proyecto político más incluyente y capaces de transformar las estructuras de poder existentes, dotadas como están de una importante capacidad represiva). Las solidaridades de clase son cada vez más difíciles de producir a la luz del tipo de individualismo que se genera por la sociedad del mercado neoliberal (Dardot y Laval, 2014), junto con el cultivo sistemático de divisiones étnico-raciales y culturales-religiosas por parte de los arquitectos de la política del odio.

Por consiguiente, es imprescindible que prestemos atención a los conflictos y resentimientos que se manifiestan dentro de las clases populares, ya que no son simplemente productos de manipulación desde arriba, sino también consecuencias de las dificultades cotidianas de vivir en precariedad en un ambiente de desigualdad social difícil de revertir.

\section{Fuentes}

Brum, Eliane

2018 "Como enfrentar o sangue dos dias", en $\mathrm{El}$ País, 16 de marzo <https: / / brasil.elpais.com/ brasil / 2018/03/26/politica/ 1522080125

DARDOT, PierRe 945009.html> [28 de marzo de 2018].

Y CHRISTIAN LAVAL

2014 The New Way of the World: On Neoliberal Society, Verso, Londres y Nueva York, $352 \mathrm{pp}$.

GLedHILL, JoHN

2019 "Capitalism, the Politics of Hate, and Everyday Cosmopolitanisms", en Critique of Anthropology, vol. 39, núm. 3, pp. 310-328.

Gledhill, John

y Maria Gabriela Hita

2014 “¿Las redes de organización popular aún pueden cambiar la ciudad? El caso de Salvador, Bahía, Brasil”, en Mercedes Di Virgilio y Mariano Perelman (comps.), Ciudades latinoamericanas: desigualdad, segregación y tolerancia, Consejo Latinoamericano de Cien-

GLedHILl, JoHN cias Sociales, Buenos Aires, pp. 85-112.

y Maria Gabriela Hita

en prensa "Political parties, big business, social movements and the 'voice of the people': Views from above and below on the crisis created by the 2016 Coup in Brazil", en Marina Gold y Alessandro Zagato, After the Pink Tide: Corporate State Formation and New Egalitarianisms in Latin America, Berghahn, Nueva York y Oxford.

Gohn, Maria da GLÓRIA

2017 Manifestações e protestas no Brasil: correntes e contracorrentes na Atualidade, Cortez Editora, São Paulo, 128 pp.

Pinheiro-Machado, Rosana

2016 "Luzes antropológicas ao obscurantismo: uma agenda de pesquisa sobre o 'Brasil profundo' em tempos de crise”, en Revista de @antropologia da UFSCar, vol. 8, núm. 2, pp. 21-28.

Santos, Boaventura de Sousa

2018 "Tres bombas de tiempo que ponen en peligro a Brasil", en Página 12, 18 de octubre <https: / / www.pagina 12.com.ar/148215 tres-bombas-de-tiempo-que-ponen-enpeligro-a-brasil> [ 11 de noviembre de 2019].

Streeck, WolfGang

2016 How Will Capitalism End? Essays on a Failing System, Verso, Londres y Nueva York, 277 pp. 